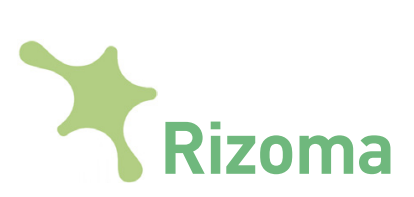

\title{
Vendem-se conselhos:
}

\author{
poder pastoral, mídia e maternidade
}

\section{Resumo}

A construção da maternidade contemporânea se desloca cada vez mais das relações tradicionais para aquelas de caráter especializado. A hipótese deste trabalho é que a mídia pode ser pensada como poder pastoral (FOUCAULT, $1988,2008)$, na medida em que se propõe a orientar as mães por meio dos conselhos de especialistas. Para pensar tal fenômeno, esse artigo traz uma análise dos textos de apresentação de produtos midiáticos sobre criação de filhos, no Brasil contemporâneo.

Palavras-chave: Poder pastoral; Mídia; Maternidade; Cultura terapêutica.

\section{Resumen}

La construcción de la maternidad contemporánea es cada vez desplaza las relaciones tradicionales a los de carácter especializado. La hipótesis es que los medios de comunicación pueden ser considerados como el poder pastoral (FOUCAULT, 1988, 2008), en promedio que se proponga para guiar las madres a través de asesoramiento de expertos. Para pensar un fenómeno tal, este artículo presenta un análisis de la presentación de textos de los productos de los medios sobre la crianza de los hijos en el Brasil contemporâneo. Palabras clave: Poder pastoral; Medios de comunicación; Maternidad; Cultura terapéutica.

\begin{abstract}
The construction of contemporary motherhood is increasingly displaced from the traditional relationships to those one of specialized character. The hypothesis of this paper is that the media can be thought of as pastoral power (FOUCAULT 1988, 2008), in that it proposes to guide mothers through expert advice. To think such a phenomenon, this article presents an analysis of the presentation texts of media products on parenting in contemporary Brazil.

Keywords: Pastoral power; Media; Motherhood; Terapy culture.
\end{abstract}

\section{Introdução}

A experiência deu lugar à especialidade. Ser mãe passou a ser tarefa aprendida para além dos domínios familiares, das experiências tradicionais. O saber que constrói a maternidade está cada vez mais longe das relações
Renata Oliveira Tomaz

1 Doutoranda em Comunicação e
Cultura, na linha de pesquisa Mídia
e Mediações Socioculturais, com
Bolsa Faperj Aluno Nota 10, pela
Universidade Federal do Rio de
Janeiro, onde concluiu o mestrado
(2011) e a graduação em Jornalis-
mo (2004). Membro do corpo de
colaboradores da revista ECO-Pós
e estagiária docente na Escola
de Comunicação da UFRJ. Tem
experiência profissional na área de
Comunicação, em mídia impressa,
online e eletrônica. Os interesses de
pesquisa se concentram nas áreas de
infância, juventude, subjetividades
contemporâneas, culturas urbanas, maternidade e mídia. 
entre mãe e filha, dos acordos geracionais, e cada vez mais perto da fala dos peritos. Revistas, colunas de jornais impressos, quadros de emissoras de rádio, programas de $\mathrm{TV}$, blogs, sites especializados, livros, guias e manuais classificam crianças em fases de desenvolvimento que deverão ser coordenadas por pais e principalmente mães. São dicas, conselhos, procedimentos e passo-a-passos que procuram conduzir os responsáveis por aquilo que se tornou uma grande empreitada: a criação de filhos.

Seria bastante simplista afirmar que se trata de mais um nicho de mercado explorado, nesse caso, por empresas do ramo da produção de conteúdo - embora isso não possa ser negado. Entretanto, a oferta e, certamente, a procura de tais produtos acontecem no interior de uma cultura formada no âmbito de transformações agudas nas sociedades modernas. A prevalência dos especialistas está bem mais ligada a uma dinâmica sociocultural cada vez mais desvinculada das grandes figuras de autoridade do que dos planos de marketing. Nessa perspectiva, esse trabalho propõe uma abordagem para pensar a construção da maternidade fora de um âmbito tradicional e dentro de um especializado.

Por meio de uma análise dos discursos de apresentação ${ }^{2}$ de revistas, programas de rádio e TV e portais segmentados, será mostrado de que forma esses produtos se oferecem, que necessidades eles se propõem a suprir, a quem se dirigem e qual interlocução propiciam. Trata-se, então, de uma análise que irá considerar, nesse sentido, as possibilidades de subjetivação. Com o objetivo de compreender a amplitude do papel social dos aparatos midiáticos na contemporaneidade, o conceito foucaultiano de poder pastoral será usado como chave teórica na análise do referido fenômeno ${ }^{3}$.

$\mathrm{O}$ artigo irá, antes de tudo, situar historicamente essa virada científica da maternidade e apresentar o conceito de poder pastoral na esfera das sucessivas rupturas culturais do século XX. Em seguida, alguns pontos da análise dos textos que apresentam os veículos voltados para a criação de filhos serão destacados, buscando-se entender como a mídia reivindica para si o lugar de autoridade para instruir tal tarefa.

\section{A virada científica da maternidade}

A procura pelos aparatos midiáticos em busca de conselhos e diretrizes voltados para a criação de filhos não é algo recente. Muito menos algo que sempre existiu. É, de fato, historicamente situada e, no Brasil particularmente, remete-nos ao final do século XIX. Foi nesse momento que a burguesia do país ansiava por concretizar a jornada do progresso, por meio de cidadãos civilizados, os quais, naquele momento, começavam a ser vistos como resultado de um investimento contínuo da família e do estado, desde tenra idade. A criança, então, saía de sua invisibilidade doméstica, privada, para o exercício de um novo papel social: uma promessa de futuro. E foi a mulher, nesse contexto, a escolhida para desenvolver o papel de formadora desse indivíduo. É nesse momento que começam a surgir semanários e quin-
2 Entende-se por apresentação textos como "Quem somos", os de mídia-kit e os de declarações de missão e

valores, utilizados para qualificar o propósito de determinado site, revista ou programa de TV ou rádio.

3 Nota de agradecimento ao professor que ministrou o curso em que esse argumento foi discutido coletivamente e, nesse sentido, onde surgiu a ideia deste artigo. 
zenários voltados para as mães, convocando-as a assumir a responsabilidade pela saúde do filho e por sua formação moral (SCAVONE, 2004; FREIRE, 2008; MARTINS, 2008; TOURINHO 2009; CASTRO, 2013). Isso não quer dizer que antes as mulheres não cuidavam das crianças. Pelo contrário. $\mathrm{O}$ fato de apenas a mulher poder engravidar, parir e amamentar dava a ela uma proximidade e convivência inevitáveis com os filhos. Em um ambiente prémoderno, as mulheres dividiam a tarefa não só de cuidar dos bebês, mas delas próprias. O saber estava nas figuras femininas das parteiras, das avós, das comadres, das vizinhas, das rezadeiras. Elas orientavam a gestação, o parto, os primeiros cuidados com o bebê e qualquer assunto relacionado à saúde da criança.

Mas a urgência do desenvolvimento chancelou à ciência uma autoridade que penetrou as mais distintas áreas da sociedade moderna, inclusive a criação de filhos. Não se tratava apenas de criar linhas férreas ou ampliar o alcance de equipamentos de comunicação. A marcha da evolução exigia a criação de um ambiente propício ao desenvolvimento físico, moral e intelectual do ser humano, desde sua gestação. Ganha força a figura do médico - o que também de certa forma conferia distinção à burguesia que se formava - por meio do exercício da pediatria e da puericultura. Seus ensinos circulavam através de periódicos e manuais a partir dos quais os saberes tradicionais femininos, antes aceitos e legitimados, eram confrontados pelo conhecimento científico dos médicos homens - a partir desse momento, os detentores do conhecimento necessário para ensinar as mães como gerar e criar filhos sadios e civilizados. Essa alteração é vista por Julia Tourinho como um marco para pensar de que forma a maternidade deixou de ser uma experiência feminina transmitida de geração em geração para se tornar um "saber emergente" da medicina ou ainda "um discurso masculino sobre mulheres" (TOURINHO, 2006, p. 17), disseminado por meios de comunicação massivos. Já Maria Martha Freire (2008) acredita que não se tratou de uma simples dominação masculina, mas de uma mudança que congregou médicos, juristas, educadores e também feministas e mães. Para ela, a valorização da maternidade permitiu que o papel social do feminino também ganhasse valor e levasse para o espaço público a questão da maternidade, amplificando tanto o papel da mulher quanto da criança.

São exemplos dessa nova dinâmica os jornais Mãi de Familia, editado pelo médico higienista Carlos Costa entre os anos 1879 e 1888 no Rio de Janeiro, e A família, publicado entre 1888 e 1894, em São Paulo; as revistas Vida Doméstica e Feminina, que circularam nos anos 1920 no Rio de Janeiro; e os manuais Vamos criar seu filho (1938), de Carlos Prado, Cartilha às mães (1935), de José Martinho da Rocha, e $A$ vida do bebê (1941), de Rinaldo de Lamare. Este último, conhecido como "a bíblia" para mães e pais, está em sua $43^{\text {a }}$ edição e já vendeu cerca de 5 milhões de exemplares no Brasil. O autor, alguns anos mais tarde, faria parte do Conselho Científico da Bloch Editores, que lançou em 1968 a revista Pais \& Filhos, a primeira do gênero no país, ainda em circulação. Desde a segunda metade do século XX, o número de produtos midiáticos com esse apelo não para de crescer. Além do 
acesso às inúmeras traduções, as famílias brasileiras assistem a uma ampla produção de diretrizes e conselhos para a tarefa de cuidar e educar filhos. Depois de Pais \& Filhos, outras revistas impressas surgiram e acabaram ou permaneceram - caso da Crescer (Editora Globo), atual líder do segmento, criada em 1993. O assunto é bastante explorado na internet por meio de sites especializados, blogs e perfis dos mais diversos nos sites de redes sociais. Há também uma variedade considerável de aplicativos para smartphones e tablets, como calculadoras de fertilidade e lista de enxoval. As principais emissoras FM de notícia do país (CBN e Band News) mantêm boletins sobre a criação de filhos, e a TV, seja em programas temáticos, nas novelas ou reality shows, aborda o assunto recorrentemente.

É deste universo que provém o corpus deste artigo: as revistas Pais \& Filhos (Manchete) e Crescer (Globo), os portais Bebê.com.br (Abril) e Baby Center Brasil, a versão brasileira do programa Supernanny (SBT) e a coluna Seus Filhos (Band News FM). A escolha dos produtos procurou contemplar mídias impressas, eletrônicas e online de ampla cobertura. As revistas Pais \& Filhos e Crescer são as únicas voltadas para a criação de filhos atualmente em circulação nacional. A coluna diária Seus filhos, da terapeuta Rosely Sayão e da jornalista Inês de Castro, na Band News FM, é transmitida para quatro das cinco regiões do país, e o programa semanal Supernanny na época do levantamento era veiculado semanalmente em rede nacional pelo SBT. Os portais Baby Center Brasil e Bebê.com.br, dentre os pesquisados, mostraram-se os de maior volume de informação, com atualizações diárias. Das revistas, foram utilizadas as declarações de valores e missão; dos portais, as descrições de "Quem somos" e "Sobre"; já dos programas de TV e rádio foram utilizados os textos de apresentação nos sites de suas respectivas emissoras. Foram consultados, ainda, os mídia-kit das revistas e dos sites - materiais produzidos para captação de anunciantes. O objetivo é compreender de que forma esses produtos se apresentam - "vendem-se" - como espaços legítimos e autorizados na construção da maternidade contemporânea.

\section{Cultura terapêutica e poder pastoral}

Os termos encontrados no material analisado "ajudar", "apoiar", "orientar", "informar", "compartilhar", "dar suporte", "inspirar" e "atender" formam juntos um campo semântico: o do aconselhamento. Trata-se de uma área próspera, que ganhou força no mercado editorial brasileiro na segunda metade de século XX, especialmente nos anos 1990, mas que também alcançou o segmento de periódicos de uma forma bem mais sistemática, no que João Freire Filho chama de jornalismo de autoajuda (FREIRE FILHO, 2011). As promessas de orientação dos veículos investigados estão balizadas por um conhecimento científico, garantido pela presença dos especialistas advindos de diferentes campos do saber: pediatria, psicologia, psicanálise, nutrição, pedagogia, neurologia e fonoaudiologia, entre outros. É o que está posto, por exemplo, na declaração de valores da revista Crescer": "Busca-
${ }^{4}$ As declarações de valores da Crescer e de missão da Pais \& Filhos são impressas em todas as edições na página do sumário. 
mos e filtramos as informações mais relevantes nas áreas de saúde, ciências, educação e comportamento. Consultamos as fontes mais seguras e usamos dados científicos de maneira responsável”. Em Pais \& Filhos, a declaração de missão assegura sua intenção primordial em uma interlocução direta com leitores e leitoras: "Queremos ajudar você a aproveitar essa fase da vida [a infância dos filhos], que passa muito rápido, mesmo. Nosso papel é estar ao seu lado, buscando respostas, informando e compartilhando experiências". O mídia-kit do site Bebê.com. $b r^{5}$ o define como uma "verdadeira central de soluções para as mães, alimentada com reportagens de todas as publicações Abril". A relação estabelecida pressupõe uma necessidade a ser diagnosticada e, por consequência, suprida pelos veículos.

Tais dinâmicas estão inscritas no que Frank Furedi (2004) chamou de cultura terapêutica. Com isso, não quis se referir ao aumento inegável do número de pessoas no século XX que buscavam tratamento psíquico. Para além disso, ele defendeu que as alterações culturais pelas quais as sociedades contemporâneas passaram nas últimas décadas possibilitaram a formação de um etos terapêutico, ou seja, uma lógica, uma estratégia de práticas sociais baseadas em uma perspectiva psicológica da vida, formatada a partir de um eu interiorizado. A maneira como o mídia-kit do Baby Center caracteriza seus serviços para os anunciantes em potencial pode ser usada como exemplo do que Furedi tratou tão bem. O texto afirma que o portal e suas versões em 11 idiomas (uma delas o português brasileiro) "provê acesso aos corações e mentes das mães" e que seus editores e especialistas entendem "profundamente seus desafios [das mães], preferências e necessidades" ${ }^{\circ}$. Os elementos psíquicos dos indivíduos passam a figurar, nesse sentido, em distintos setores da sociedade não apenas como algo característico deles, mas como fatores fundamentais na gestão da vida.

Lipovetski (1988) compreendeu essa nova percepção como uma sensibilidade terapêutica. Para o filósofo francês, a propulsão ideológica, política e intelectual dos anos 1960 não gerou as mudanças prometidas, levando a uma frustração social e política generalizada, de onde, segundo ele, só a esfera privada parece sair vitoriosa. Foi como se cuidar da própria vida tivesse se tornado a única coisa que restou às sociedades que ansiavam revolucionar o mundo. Diante das responsabilidades individuais centradas em um self que demanda cada vez mais investimentos, os sistemas especializados (GIDDENS, 2002) se formam estrategicamente no interior de sociedades ávidas por conselhos sobre como agir em diferentes áreas da vida. A gradativa passagem de uma maternidade tradicional para uma especializada está inserida nesse contexto.

Foucault $(1988,2008)$ chamou de pastoral o poder que não age externamente, coibindo e proibindo, mas internamente, formando consciência e, portanto, subjetividade. O conceito é baseado nos modos pelos quais esse poder, ao longo da Idade Média, no âmbito do Cristianismo, permitiu simultaneamente a conduta da ovelha em particular e do rebanho, ou seja, do indivíduo e do todo em que ele estava inserido (FOUCAULT, 1988, 2008). Segundo o autor, essa tecnologia de conduta teria se sofisticado sobrema-
${ }^{5}$ Disponível em http://publiabril. abril.com.br/marcas/bebe-com-br/ plataformas/site. Último acesso em 23/03/2016.

\footnotetext{
${ }^{6}$ Disponível em http://www.babycentersolutions.com/docs/BabyCenter_2014_Media_Kit.pdf. Último acesso em 23/03/2016.
} 
neira a ponto de ultrapassar seu aspecto religioso, ainda que permanecesse nessa esfera, especialmente a partir da prática da confissão:

\begin{abstract}
Durante muito tempo [a confissão] permaneceu solidamente engastada na prática da penitência. Mas, pouco a pouco, a partir do protestantismo, da Contra-Reforma, da pedagogia do século XVIII e da medicina do século XIX, perdeu sua situação ritual e exclusiva: difundiu-se; foi utilizada em toda uma série de relações: crianças e pais, alunos e pedagogos, doentes e psiquiatras, delinquentes e peritos. As motivações e os efeitos dela esperados se diversificaram, assim como as formas que toma: interrogatórios, consultas, narrativas autobiográficas ou cartas, que são consignados, transcritos, reunidos em fichários, publicados e comentados. Mas a confissão se abre, senão a outros domínios, pelo menos a novas maneiras de percorrer tais domínios. (FOUCAULT, 1988, p. 62).
\end{abstract}

Utilizada para compreender a construção da sexualidade na Modernidade, a metáfora do poder pastoral ajudou Foucault a entender como os distintos saberes fizeram uso de suas práticas para construir verdades sobre o sexo. Segundo ele, a verdade construída na prática da confissão, por exemplo, não estava exatamente na narração de si, mas na codificação, na interpretação que completaria sua formulação a partir do exame de "um conjunto de sinais e de sintomas decifráveis" (FOUCAULT, 1988, p. 64), por "quem é devido e por quem é, ao mesmo tempo, seu detentor e responsável" (Ibidem, p. 66). É nesta relação que surge a imagem do pastor, um guia de conduta, uma voz que aponta para o bom caminho.

Esses modelos de autoridade construídos ao longo do século XIX, entretanto, têm apresentado sinais de desgaste, sofrendo o que se poderia chamar de uma crise de autoridade ${ }^{7}$, um conjunto de eventos que permitiram uma rachadura na imagem de figuras como pai, mãe, educadores, sacerdotes e o próprio Estado. Como na perspectiva foucaultiana todo exercício de poder possibilita e suscita resistência, é possível pensar que esse esfacelamento não provocaria a extinção do poder pastoral, mas seu deslocamento. Isso pode estar ligado ao que o filósofo chamou de "necessidade de conduta". Em sua visão, a urgência por individualidade depende de uma subjetivação (FOUCAULT, 2008, p. 310), "é preciso tornar-se sujeito para se tornar indivíduo", mas “como se tornar sujeito sem ser sujeitado?". Isso significa dizer que "a grande crise do pastorado e os assaltos das contracondutas que premiram essa crise não levava a uma rejeição global de toda conduta, mas a uma busca multiplicada para ser conduzido". Ou seja, ao mesmo tempo em que há oposição ao seu exercício (um reconhecimento de sua ação), há uma predisposição em ser conduzido que não é natural, mas propiciada pelas urgências de individualização da própria sociedade.

É nesse sentido que, mesmo reconhecendo-se o enfraquecimento crescente de figuras como os pais, os líderes religiosos, o Estado e os educadores, pode-se procurar a ação do poder pastoral em outros locais - nesse caso, a mídia, tomada aqui como um lugar a que os indivíduos podem acorrer para encontrar modos de conduta e procedimento por meio dos quais poderão subjetivar-se. É preciso salientar, entretanto, que os elementos a partir dos quais Foucault (2008) aplicou a ideia de poder pastoral para investigar os
${ }^{7}$ Giddens (2007) pensa a crise de autoridade na perspectiva do que ele chama de democracia das emoções. Para o autor, os contratos tradicionais que regiam as relações interpessoais foram substituídos pelo que ele chama de relacionamento puro cuja chave de eficácia e felicidade estaria na intimidade. Essa capacidade de se abrir, confiar no outro, dialogar em bases iguais passa a ser apontada como fundamental para um relacionamento bem-sucedido. Nesse sentido, há similaridade com o que se pressupõe num regime de democracia, levando-se em conta que este modelo de relacionamen-

to requer: igualdade de direitos e obrigações entre as partes, respeito pelo outro, comprometimento com seu bem-estar, compreensão diante de uma opinião diferente, insistên-

cia no diálogo, confiança mútua

e ausência de poder arbitrário, coerção ou violência - qualidades que correspondem aos valores de uma política democrática. Quando

esta realidade de bases iguais se apresenta nas relações entre pais e filhos ou professores e alunos, por exemplo, pode surgir uma crise de autoridade. 
processos de subjetivação nas sociedades modernas carecem de uma releitura em sua apropriação na contemporaneidade ${ }^{8}$. Além disso, dizer que houve uma erosão na imagem das figuras de autoridade não significa dizer que elas não existam mais, muito menos que perderam seu lugar. O que se defende aqui é a existência e, em certo contexto 9 , a prevalência de outras vozes autorizadas a instruir especialmente as mães na criação de filhos. É em busca delas, particularmente, que os produtores desse tipo de informação estão.

\section{A colonização dos expertos}

Há mais dez anos, foi criado na Inglaterra o programa Supernanny, apresentado pela educadora Jo Frost. A aceitação do reality show que mostrava uma expert em crianças ensinando pais desorientados a dominar e disciplinar seus filhos pequenos resultou na produção de versões em dezenas de países. No Brasil, a pedagoga argentina Cris Polli apresentou o programa no SBT entre 2006 e 2010 e, após um intervalo de três anos, voltou para a última temporada em 2014 a fim de "socorrer pais e mães que não sabem mais o que fazer para impor disciplina aos próprios filhos" ${ }^{\prime 10}$. Durante os episódios semanais, mães e pais eram encorajados a estabelecer uma rotina que privilegiasse a disciplina na vida das crianças. Dentre os dilemas apresentados pelos responsáveis estavam a recusa das crianças em se alimentar na hora certa com alimentos adequados, a dificuldade em fazê-las dormir e o incômodo trazido pelas birras e pirraças. Os produtos voltados para a criação de filhos vêm, portanto, atender a uma urgência de saber, não mais localizado exclusivamente nos pactos geracionais ou nas grandes instituições modernas, mas predominantemente nos discursos científicos.

O boletim Seus filhos, da Band News FM, além dos pais e das mães, afirma ser voltado para educadores e "toda sociedade". Os mídia-kits dos sites Baby Center Brasil e Bebê.com.br definem a mulher que está tentando engravidar, está grávida ou já tem filhos pequenos como sua potencial e real consumidora. Enquanto o primeiro disponibiliza informações de 0 a 3 anos, o segundo o faz de 0 a 6 anos. No caso das revistas impressas, mesmo requerendo a posição de um veículo de comunicação voltado para a família, são nitidamente revistas femininas com predominância de temática para a mulher-mãe. Embora de uma maneira geral os textos analisados confirmem que o público desses produtos seja formado por pais e mães, os mídia-kits dos sites e das revistas são categóricos em apontar a mulher-mãe-consumidora, entre 25 e 35 anos, comumente inserida no mercado de trabalho e pertencente às classes $\mathrm{AB}$ como seu principal alvo ${ }^{11}$. A situação descrita pode ser conferida na declaração de Crescer, onde se autointitula "a companheira da mulher que tem filhos - e que ama ser mãe - mas que também quer cuidar de si própria, estudar, trabalhar, namorar. E dos pais que entendem a importância de participar do desenvolvimento de seus filhos" (grifo meu). O texto da revista elucida uma compreensão distinta do papel do pai e da mãe. Em primeiro lugar, fala-se com uma mulher que ama ser mãe e que precisa
${ }^{8}$ No poder pastoral moderno, o indivíduo produzia uma narrativa de si (confissão, relato, respostas a um interrogatório), que precisaria ser decodificada por uma figura autorizada a fim de que o desejo oculto pudesse ser revelado e o indivíduo culpabilizado por desejar ou fazer algo proibido. Cada um, portanto, necessitava de alguém que pudesse entender as verdades em sua fala e, em seguida, ser-lhe um guia de consciência, alguém que iria afastá-lo/ la da anormalidade, da doença ou da perversão, instruindo para o bom caminho da normalidade, da cura, da salvação. Com a crise do poder pastoral ou da autoridade, coexistindo com uma série de rupturas socioculturais, a culpa começa a esmaecer, pois não há mais desejo proibido e, por isso, perde-se a necessidade de extrair a verdade do sujeito. Logo, o indivíduo que sofre não é mais o culpado pelo seu próprio sofrimento, mas o outro, que o impede de satisfazer seus desejos. Nesse sentido, a confissão dá lugar ao testemunho - a narrativa de si que revela o sofrimento causado não pelo que sofre, mas por alguém que o fez (faz) sofrer. O indivíduo torna-se seu próprio guia de consciência. É ele quem deve descobrir e decidir por si mesmo se precisa de cura ou de salvação. É ele também quem decide dar vazão a seus desejos e encontrar a melhor maneira de alcançá-los.

9 Trata-se de um quadro relativamente comum, por exemplo, nos grandes centros urbanos, onde as famílias se deparam com o nascimento ou a criação de filhos longe dos tradicionais espaços de segurança e onde os especialistas e peritos vão

se tornar um grande amparo. Em regiões interioranas em relação aos grandes centros, o papel das figuras

tradicionais de autoridade ainda é extremamente importante na constituição da maternidade. Além disso,

o acesso aos aparatos midiáticos como novos espaços dessa construção está inserido em um conjunto de práticas limitadas aos que possuem

recursos necessários para realizá

-las. Nesse sentido, a maternidade especializada torna-se um elemento de diferenciação social. 
equilibrar esse papel com os demais. Já o pai, para ser aceito, basta entender que é importante participar da criação dos filhos. A expressão se repete em inúmeros discursos que apontam a mãe como a principal responsável na formação da criança e o pai como alguém que está sendo cada vez mais solicitado a participar dessa tarefa, e não assumi-la ou ser responsabilizado por ela. Há um protagonismo materno que, certamente, não é inventado pela revista, mas aparece nela como um reflexo da própria compreensão social da responsabilidade da mulher, historicamente situada. Algo semelhante pode ser visto na declaração de Pais \& Filhos, que a define como "uma revista para a família, para a grávida, para o grávido e para os pais de crianças de até 12 anos. Para quem engravida de forma tradicional, para aqueles que correm atrás do sonho com a ajuda da reprodução assistida e também para quem decide adotar". Mas em outro trecho dirige-se à mulher: "você pode ser uma boa mãe se tiver parto normal ou cesárea, se tiver amamentado ou não, se adotar a dieta vegetariana ou se optar por comer carne. Lutamos pelo direito de você poder fazer suas próprias escolhas". A última frase chama atenção por duas razões: primeira, a revista revela não só sua interlocução com a mulher, mas se apresenta como uma defensora de seus direitos; em segundo lugar, introduz a questão das escolhas individuais como um valor contemporâneo - o que também aparece no texto de apresentação do Baby Center Brasil: "procuramos apresentar vários pontos de vista sobre um mesmo tema para que você possa conhecê-lo mais a fundo e tomar as decisões que melhor se encaixem nas necessidades de sua vida e família".

É, no mínimo, curioso pensar que, diante de tantas demandas sociais, a revista decida se comprometer a lutar por um direito individual e não vinculado a questões da mulher especificamente. A afirmação está alinhada à concepção contemporânea de liberdade. Desvinculado das instituições modernas e das figuras de autoridade, o indivíduo está livre para decidir quem ser e como estar no mundo. Para Rose (1999, p. 84), a "liberdade como autonomia" aparece na "capacidade de realizar os desejos na vida secular, desenvolver todo o potencial através do próprio esforço, determinar o curso da própria existência por meio de atos de escolha". Para o autor inglês, as tecnologias do consumo foram fundamentais na concepção de uma lógica a partir da qual fazer determinada compra torna possível ao indivíduo aderir a um estilo de vida e comunicá-lo na forma de uma narrativa de vida coerente com as escolhas feitas. A construção e a manutenção desse estilo de vida se baseiam nas orientações dos especialistas, que não só fomentam desejos, mas também oferecem meios de alcançá-los. De acordo com Lasch (1979), há uma recorrência aos expertos, que passam a ser cada vez mais entendidos como figuras que podem ajudar os indivíduos nos recorrentes processos de escolha - não dizendo o que escolher, mas ensinando-lhes o que é necessário, valoroso, desejável.

"Impor disciplina", "criar", "educar", "cuidar" e "formar" são ações que se mostram equivalentes nos discursos de apresentação dos veículos analisados. Elas indicam "a difícil e maravilhosa tarefa que é criar um filho" (Baby Center). E é preciso cumpri-la a fim de que os filhos "contribuam
${ }^{10}$ Disponível em http://www.sbt.com. br/supernanny/oprograma/. Último acesso em 23/03/2016.

11 *Bebê.com.br: Público feminino (72\%) / Idade: 25 - 34 (35,2\%), $35-44(31,1 \%), 15-24(20,5 \%)$ *Crescer: Público feminino (64\%) / Idade: 25 - 34 (38\%), 45+ (21\%), 35 - $44(20 \%) *$ Pais \& Filhos: Público feminino (78\%) / Classe social: AB (50\%), C (43\%)/ Dados disponíveis em http://publiabril.abril.com.br/ marcas/bebe-com-br/plataformas/ site, http://crescer.globo.com/ midiakit/arquivos/MidiaKit_Crescer_2013-PT.pdf e http://www. paisefilhos.com.br/wp-content/ uploads/2015/06/midiakit_2016_digital.pdf. Último acesso em $23 / 03 / 2016$ 
na formação de um mundo melhor (...) façam a diferença e sejam pessoas melhores, assim alcançaremos um futuro mais equilibrado e harmônico", desafia Crescer. Segundo declaração de missão de Pais \& Filhos, "ninguém educa sozinho: precisamos da ajuda de avós, tios, compadres, amigos, pediatras, professores e... revista, site, iPad e aplicativos para celular! Cada um com seu papel" (grifo meu). As tradicionais figuras de autoridade começam a ceder espaço para as novas, que não estão especificadas (em vez de dizer médicos, psicoterapeutas, neuropediatras etc, o texto cita os meios) no texto acima, mas amplamente dispostas nos discursos propagados por esses media.

Para Vilhena et. al (2013), a penetração dos peritos com um extenso rol de tarefas parentais contribui para que a maternidade se torne em grande medida uma empreitada angustiante. Ao reconhecerem que, na cultura contemporânea, há um ideal de perfeição dificilmente atingível, as autoras recorrem ao conceito de "mãe suficientemente boa", de Donald Winnicott. De acordo com elas, o psicanalista usou o conceito para criticar a panaceia do progresso no início do século XX, em que mães eram totalmente responsabilizadas pela formação de um indivíduo perfeito por meio do cumprimento de uma série de normas. Ele buscou mostrar que não se tratava de competências extraordinárias, mas de uma vivência relacional que iria se desenvolver dia após dia com a mãe buscando, do seu jeito, suprir as necessidades e demandas do filho.

Compreendemos que, para Winnicott, a 'mãe devotada comum' (1978/1956), juntamente com o pai do bebê, é capaz de criar o ambiente suficientemente bom, não se reduzindo, tão somente, ao biológico ou ao psicológico, e, tampouco, às representações sociais do materno/feminino (...) A 'mãe suficientemente boa', tampouco é excessiva, antecipatória, intrusiva ou uma imagem ideal. A palavra 'suficiente' foi empregada para designar 'o bastante'; ou seja, apenas o que lhe parecia hábil e adequado aos cuidados necessitados pelo infante, em cada ocasião". (VILHENA, J. et al., 2013, p. 115-116).

As autoras lançam mão desse conceito na contemporaneidade para fazer uma crítica ao que chamam de práticas produtivistas travestidas de táticas de estímulo ao desenvolvimento da criança. Segundo elas (VILHENA et. al, 2013, p. 114), "há tal urgência no 'fazer' que, muitas vezes, o 'tempo de ser' se perde (...) a crescente colonização da esfera familiar pelas chamadas expertises transforma a parentalidade em uma tarefa basicamente da ordem da ação, da falta e da dívida". Vilhena et. al (2013) acreditam que não se trata apenas de necessidades estritas para o exercício da parentalidade, mas da vigência de uma lógica econômica que rege valores e princípios contemporâneos, chamada por elas de ideologia da eficiência.

Correa (2010) chegou a uma compreensão semelhante ao estudar um aumento considerável na busca por diagnósticos de patologização de crianças, no âmbito dos transtornos psíquicos. Para ela, as crianças têm sido constantemente avaliadas segundo sua capacidade de atender às demandas de uma alta performance, entendida como bom rendimento escolar, compreensão e aplicação dos modos adequados de agir e superação de limites 
em um ambiente extremamente competitivo. De acordo com a autora, pais, educadores e especialistas não questionam essa lógica produtivista aplicada às crianças porque tais exigências se vinculam a uma visão adultocêntrica do mundo, ainda que se diga que tais atitudes visam ao desenvolvimento da própria criança. São demandas adultas que de fato estão sendo supridas por meio de uma ordem onde vigoram padrões de um mundo "pragmático e obcecado por resultados" (CORREA, 2010, p. 104). Sendo assim, os imperativos de "criar", "educar", "formar" e "impor disciplina" revelam um alto padrão de exigência que, para ser atendido, demandará a expertise dos peritos, cada vez mais acessados e procurados.

De volta ao conceito foucaultiano de poder pastoral, pode-se perceber a permanência de sua lógica na contemporaneidade. A partir de ideais de ser, surgem necessidades e, junto delas, quem mostre formas (opções) de supri-las. As novas mídias e tecnologias ampliaram ainda mais o acesso aos especialistas: "Estamos na revista impressa, nos tablets, na internet, nos smartphones, nas redes sociais, na rádio, em livros e eventos", anuncia Crescer. Há, portanto, um deslocamento em processo do poder pastoral. As novas figuras de autoridade já encontraram novos lugares para se alojar e, de lá, amenizar não o sofrimento da culpa, mas a angústia da ansiedade.

\section{Considerações finais}

Dos produtos pesquisados, apenas as revistas e o site Bebê.com.br possuem slogans. Com o mote de "O site mais completo sobre bebês do Brasil", a página da editora Abril "vende-se", oferecendo informações. Ao todo, sete editorias oferecem um vasto conteúdo sobre alimentação, saúde, moda, educação, família, higiene e beleza e programa para gravidez. Pais \& Filhos e Crescer, embora tenham slogans obviamente distintos, se alinham nos valores propagados. Enquanto a primeira se autodefine como "A revista que acredita que é possível criar famílias felizes", a segunda garante: "Informação e inspiração para mães e pais". É fato que tanto uma quanto outra estão conferindo autoridade a novas figuras, mas sem cortar seu vínculo com uma ideia moderna de família. Pode-se inovar, pode-se ouvir novas vozes, pode-se criar novos espaços de onde essas falas serão ouvidas, mas desde que a família continue ocupando o seu lugar. As figuras de autoridade sofreram, como dito no início, uma rachadura em sua imagem, mas assim como o poder pastoral não desapareceu - ao contrário se realocou - elas também não foram extintas, mas sim reconfiguradas pela cultura contemporânea.

O que se viu até aqui foi que as estratégias pelas quais os modos de ser mãe eram operados foram alteradas, passando de um modo tradicional para um modo especializado de maternidade. A transformação foi pensada à luz do conceito de poder pastoral, segundo o qual a produção de subjetividade é resultado do exercício de um poder que não proíbe, mas se oferece para salvar e para mostrar o bom caminho. Embora tal conceito tenha sido formulado por Foucault em referência a figuras que já não gozam da mesma 
autoridade, ele ainda pode ser útil para compreender como as sociedades contemporâneas conceberam novos atores que desempenham o papel não de dirigir as consciências, mas de oferecer saberes necessários para os sucessivos processos de escolha do indivíduo. E é a própria demanda por individualidade, ancorada na sujeição a regras e práticas sociais e culturais, que sustenta a permanência de elementos que atuam na condução da conduta.

Essas novas figuras não estão na família, no Estado, na escola, na religião. Elas reivindicam a posição de especialistas capazes de apontar necessidades e formas de supri-las. Não mais focadas em livrar o indivíduo do sofrimento causado pelo seu desejo proibido, mas em aliviar a ansiedade trazida pela incapacidade de aderir aos ideais contemporâneos. E foi na mídia que elas encontraram um amplo espaço para se desenvolverem e se tornarem vozes de verdade. A mídia como poder pastoral, portanto, é uma possível chave teórica para compreender as transformações pelas quais passaram os modos de ser e tornar-se da contemporaneidade. É também, nesse sentido, um lugar privilegiado para pensar a construção da maternidade, atravessada por exigências e demandas como gênero e classe. Como a história nos mostra, ser mãe está para além da condição biológica ou psicológica, é um arranjo social e cultural desenvolvido ao longo dos tempos e espaços; uma construção que precisa levar em conta os valores predominantes em um dado contexto sociocultural e histórico.

\section{Referências}

CASTRO, Lucia Rabello de (Ed.). O futuro da infância. Rio de Janeiro: Faperj / 7 Letras, 2013.

CORREA, Andréa. Infância e patologização: crianças sob controle. Rev. bras. psicodrama, São Paulo, v. 18, n. 2, p. 97-106, 2010.

FOUCAULT, Michel. Omnes et singulatim: towards a cristicism of "political reason". The tanner lectures on human values. Standford University, 10 e 16 out., 1979.

História da sexualidade 1: vontade de saber. Rio de Janeiro: Graal, 1988.

Segurança, território, população: Curso dado no Collège de France (1977-1978). São Paulo: Martins Fontes, 2008.

FREIRE, Maria Martha de Luna. "Ser mãe é uma ciência": mulheres, médicos e a construção da maternidade científica na década de 1920. História, Ciências, Saúde - Manguinhos, Rio de Janeiro, v.15, p.153-171, jun. 2008.

FREIRE FILHO, João. O poder em si mesmo: jornalismo de autoajuda e a 

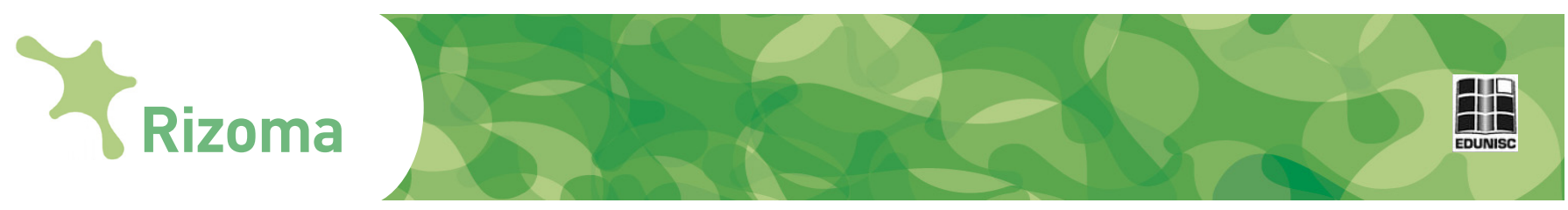

construção da autoestima. Famecos, Porto Alegre, v. 18, n. 3, p. 717-745, 2011.

FUREDI, Frank. Therapy culture: Cultivating vulnerability in an uncertain age. Psychology Press, 2004.

GIDDENS, Anthony. Modernidade e identidade. Rio de Janeiro: Zahar, 2002 .

Mundo em descontrole. Rio de Janeiro: Record, 2007.

LASCH, Christopher. The culture of narcisism: american life in an age of dimishing expectations. New York: W. W. Norton \& Company, 1979.

LIPOVETSKY, Gilles. A era do vazio. Lisboa: Relógio d'água, 1988.

MARTINS, Ana Paula Vosne. "Vamos criar seu filho": os médicos puericultores e a pedagogia materna no século XX. História, Ciências, Saúde-Manguinhos, Rio de Janeiro, v.15, n.1, p.135-154, 2008.

ROSE, Nikolas. Powers of freedom. Cambridge: Cambridge University Press, 1999.

SCAVONE, Lucila. Dar a vida e cuidar da vida: sobre maternidade e saúde. (Ed.). Dar a vida e cuidar da vida: feminismo e ciências sociais, p. 127-139. São Paulo: Editora Unesp, 2004.

TOURINHO, Julia. A mãe perfeita: idealização e realidade. IGT na Rede, v. 3, n. 5, 2006. Disponível em: http://www.igt.psc.br/ojs/viewarticle. php?id=24. Acesso em: 23/03/2016.

VILHENA, Julia. et al. Cuidado, maternidade e temporalidade: repensando os valores contemporâneos da eficiência. Cadernos de Psicanálise-CPRJ, Rio de Janeiro, v. 35, n. 28, p. 111-127, 2013. 